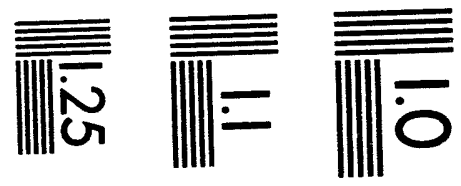

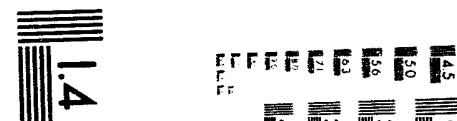

$$
\begin{aligned}
& \text { UII }
\end{aligned}
$$

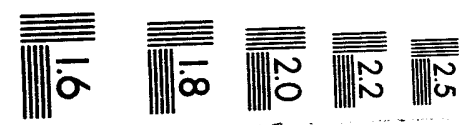



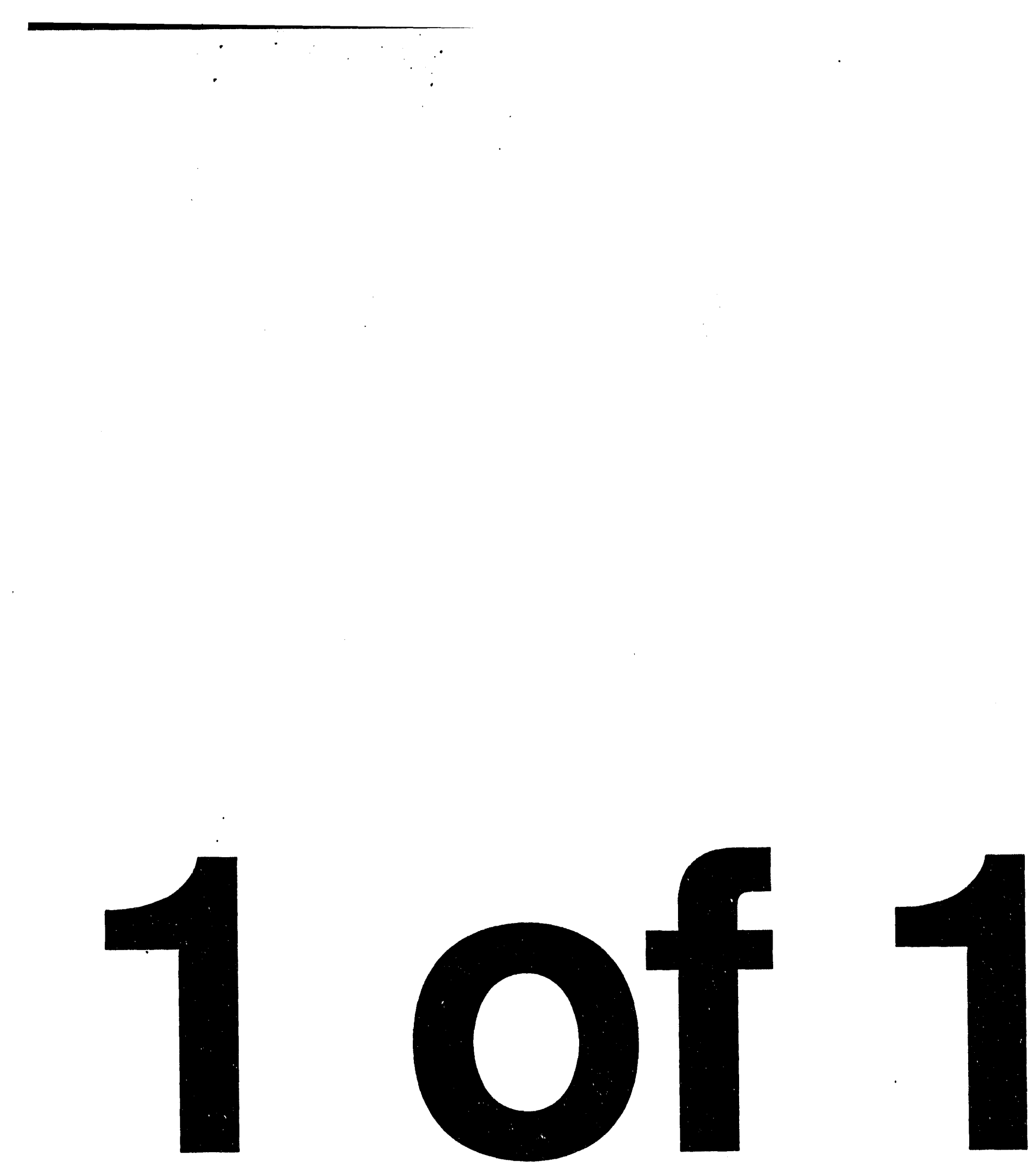


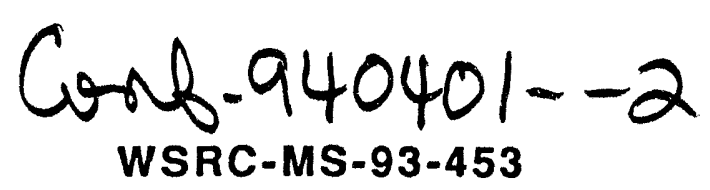

\section{AERIAL ROBOTIC DATA ACQUISITION SYSTEM (U)}

by

K. J. Hotstetter

Westinghouse Savannah River Company

Savannah River Site

Aiken, South Carolina 29808

D. W. Hayes

M. M. Pendergast

J.E. Corban

all WSRC

A document prepared for PRESENTATION AND PUBLICATION AT THE 3RD INTERNATIONAL CONFERENCE ON METHODS AND APPLICATIONS OF RADIO ANALYTICAL CHEMISTRY at Kailua-Kona, Hawaii from 04/10/94 thru $04 / 16 / 94$.

DOE Contract No. DE-AC09-89SR18035

This paper was prepared in connection with work done under the above contract number with the U. S.

Department of Energy. By acceptance of this paper, the publisher and/or recipient acknowledges the U. S. Government's right to retain a nonexclusive, royalty-free license in and to any copyright covering this paper, along with the right to reproduce and to authorize others to reproduce all or part of the copyrighted paper. 


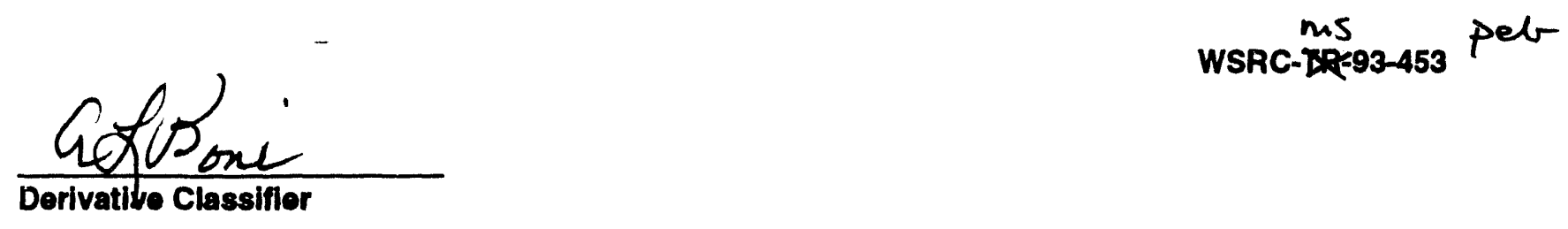

\section{Aerial Robotic Data Acquisition System( ${ }^{(U)}$}

\section{K.J. Hofstottor}

Approved by

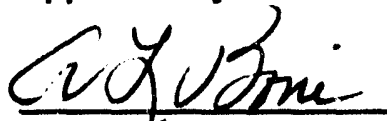

A. L. Bóni

Research Manager

Environmental Technology Section

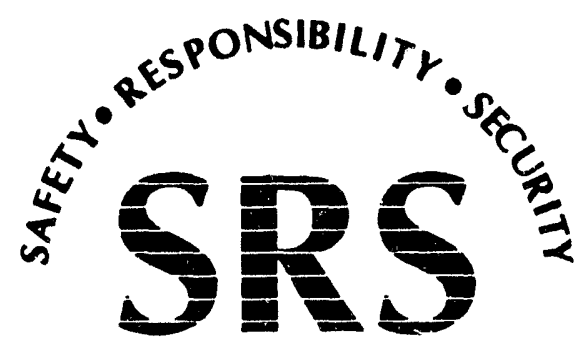

SAVANNAH RIVER SITE

Westinghouse Savannah River Company

Savannah River Technology Contor

Alken, SC 29808

DEVELOPED FOR THE U.S. DEPARTMENT OF ENERGY UNDER CONTRACT NO. DE-AC09-89SR18035 


\section{Aerial Robotic Data Acquisition System(U)}

\section{K.J. Hofstotter}

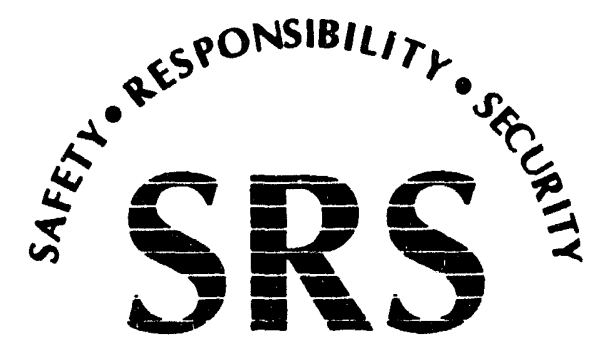

Westinghouse Savannah Rivor Company

SAVANNAH RIVER SITE

Savannah River Technology Conter

Alken, SC 29808

DEVELOPED FOR THE US. DEPARTMENT OF ENERGY UNDER CONTRACT NO. DE-AC09-89SR18035 


\section{Disclaimer}

This report was prepared as an account of work sponsored by an agency of the United States Government. Neither the United States Government nor any agency thereof, nor any of their employees, makes any warranty, express or implied, or assumes any legal liability or responsibility for the accuracy, completeness, or usefulness of any information, apparatus, product, or process disclosed, or represents that its use would not infringe privately owned rights. Reference herein to any specific commercial product, process, or service by trade name, trademark, manufacturer, or otherwise does not necessarily constitute or imply its endorsement, recommendation, or favoring by the United States Government or any agency thereof. The views and opinions of authors expressed herein do not necessarily state or reflect those of the United States Government or any agency thereof. 


\title{
AERIAL ROBOTIC DATA ACQUISITION SYSTEM
}

\section{K. J. HOFSTETTER, D. W. HAYES, M. M. PENDERGAST}

\author{
Westinghouse Savannah River Company \\ Savannah River Technology Center \\ Aiken, SC 29808 (USA)
}

and

\section{J. E. CORBAN}

Guided Systems Technologies

430 Tenth Street, NW, Suite S-002

Atlanta, GA 30318 (USA)

A small, unmanned aerial vehicle (UAV), equipped with sensors for physical and chemical measurements of remote environments, is described. A miniature helicopter airframe is used as a platform for sensor testing and development. The sensor output is integrated with the flight control system for real-time, interactive, data acquisition and analysis. Pre-programmed flight missions will be flown with several sensors to demonstrate the cost-effective surveillance capabilities of this new technology.

\section{Introduction}

Unmanned aerial vehicles (UAV) can provide an efficient means of surveying remote, and possibly hostile, environments. This technology is applicable to waste site characterizations, emergency response, facilities decommissioning, and environmental restoration assessments. For example, sites which are contaminated with chemicals or radioactive material require characterization prior to the development of remediation activities. Often, personnel are excluded from these areas due to the hazardous conditions. However, confirmatory measurements are usually required to supplement historical records of site contaminations. The development of remote monitoring techniques for direct measurement of specific chemical agents or radionuclides has been the subject of many laboratory and field projects. Hand-held sensors, transportable (mobile) systems, and fixed site monitoring stations have expanded the technologies of fieldable systems for real-time analysis. Development efforts on indirect methods for assessing site conditions also continue. Many of these sensors and methods can be conducted on an aerial platform.

The Savannah River Site (SRS) is interested in the use of UAVs as a platform for performing aerial surveys. UAVs have many advantages over manned, fixed- or rotary-winged aircraft, e.g., capital and operational costs are substantially lower, risk to area personnel during operation is lower, and the UAV can survey small areas at low airspeeds ( $<2$ meters/sec) and 
low altitudes ( $<5$ meters). The critical parameters when using a UAV platform for remote monitoring are the sensor payload (including power supply, data acquisition, and telemetry), stability of flight, minimum altitude and air speed, the ability to fly pre-programmed flight missions, and the total flight time available between refueling. The operation of the sensor packages must be independent of the flight control system.

Examples of measurement systems that might be flown on a UAV include fluorescence spectrophotometers, magnetometers, infrared thermometers, infrared sensitive thermal cameras, video and multi-spectrum imaging systems, atmospheric samplers with in-situ detection, grab samplers for laboratory analysis, real-time $\alpha-, \beta-, \gamma$, or $\eta$-radiation detectors, etc. Real-time positions correlated with sensor readings is a requirement for data interpretation. Position coordinates are provided by an on-board geographic position system (GPS) and from the external navigation system which is based on video camera triangulation and an on-board sonic range finder. Several sensor suites are being tested on this aerial platform and are discussed in the remainder of this paper.

\section{UAV Platform}

\section{Description}

The flight vehicle is a miniature helicopter with a rotor diameter of 60 inches and an empty weight of approximately 12 pounds. Maximum gross take-off weight is just over 28 pounds at dry, sea-level conditions. The aircraft is equipped with a miniature avionics package which integrates the state-of-the-art in solid-state inertial sensor technologies, microprocessors, GPS solutions, and spread-spectrum digital communications equipment. This package enables precision control of the UAV in either a pilot-assisted or fully automatic mode. The batterypowered flight control system weighs less than 6 pounds. A standardized payload bay is provided on the helicopter for installation of a variety of remote monitoring sensors. Detachable stubwings are also available for mounting of sensor elements external to the fuselage. The maximum sensor payload, after loading the fuel and batteries required for a typical mission endurance of 45 minutes, is about 5 pounds at dry, sea-level conditions. The sensor data is collected by the flight control computer either in analog or digital form, and transmitted to a ground computer via a radio link. The ground station software can be configured for real-time dispiay of the sensor data in various forms, and to store the sensor data with other measured data that defines the complete status of the vehicle. Mission control software running on the ground computer is used to plan mission objectives, and to transmit to the helicopter high level commands based on these mission objectives, current position, and other vehicle data.

\section{Sensor Suite}

Several direct reading sensors are scheduled for testing on the UAV platform. Signals from a battery powered, $\gamma$-ray sensitive, radiation survey instrument $\left[\begin{array}{l}a \\ 1 "\end{array} 1^{\prime \prime} \mathrm{NaI}(\mathrm{Tl})\right.$ 
scintillation detector coupled to a photomultiplier with signal conditioning electronics] will be interfaced to the UAV analog to digital converter and telemetered from the helicopter to the ground flight computer at the flight-test site. Only minor modifications to the commercial GM-1 radiation detector system ( $\mathrm{mfg}$. geoMetrics, Inc.) were required to interface with the UAV data communication system. Simultaneous position coordinates are received from the on-board GPS along the same data link. The GPS coordinates, altitude, and total integrated detector count rate are recorded in the data file. With the existing electronics and telemetry, pulse height analysis of the spectra cannot be performed. The instrument was originally designed to detect deposits of natural uranium ore for the National Uranium Resource Evaluation (NURE) program. (1) The instrument will detect a $1 \mu \mathrm{Ci}$ source of Cs-137 at $\approx 1$ foot (approximately $3 \mu \mathrm{rem} / \mathrm{hour}$ integrated dose rate).

Another sensor being tested on the UAV platform is a broad-band OS-600 infrared thermometer (radiometer), capable of making radiative temperature measurements. The analog signals, proportional to the surface temperatures, are converted to digital readings by the onboard analog to digital converter and telemetered to the flight control system computer. As with the radiation detector, simultaneous position and altitude readings are recorded with radiometer readings in the output file. The sensitivity of the radiometer is $\pm 1 \mathrm{deg}-\mathrm{F}$ at ambient conditions with $\approx 0.1$ steradian field of view. Only slight modifications to this commercial instrument (mfg. Omega Engineering, Inc.) are required to interface with the UAV data communication system.

A third system being considered consists of a miniature video camera mounted on the UAV chassis, complete with its own battery power supply and microwave transmitter for realtime video images. Various band-pass filters can be installed to obtain spectral information in addition to video images. A video receiver will be stationed at the ground control system and the images will be recorded on a standard video cassette recorder. A separate file of positions and altitudes will be sent to the control system computer along with the time signature for off-line correlation of the video images. The miniature video cameras and transmitters have been used at SRS and are described elsewhere. (2)

\section{Applications}

\section{$\gamma$-ray Radiation Scanning}

Aerial radiological surveys have been conducted at a number of DOE sites. These surveys are frequently made to determine the amount, extent, and transport of man-made radionuclides in the environment. In some instances, the radiations emanating from a building or facility provide independent verification of the operations being conducted or radionuclides being stored within the site. Many aerial surveys have been conducted at SRS to determine the kind, relative intensity, and spatial extent of natural and man-made radiation near select facilities and the surrounding areas. $(3,4)$ These surveys have been conducted by EG\&G Energy 
Measurements, Inc. using a large array of $\mathrm{NaI}(\mathrm{Tl})$ scintillation detectors mounted in a $\mathrm{MBB}$ BO105 helicopter. The surveys are typically conducted at altitudes of $\approx 150$ feet, with 250 feet flight line spacings at $\approx 120 \mathrm{feet} / \mathrm{second}$.

During the flight missions, spectral and position data are collected on-board the helicopter and stored on magnetic media. The tapes are then returned to a van equipped with a Radiation and Environmental Data Analyzer and Computer for preliminary field analysis. An extensive inventory of software routines have been developed as a result of these surveys to analyze the spectra and position data for radionuclide identification and quantification. These resuits are then used to generate anticipated incremental exposure rates at 1 meter above ground level corrected for terrestrial background radiation and cosmic rays. These algorithms and data analysis procedures are well documented and can be applied to the UAV radiation surveys.

\section{Thermal Plume Mapping}

Temperatures measured remotely by infrared radiometry can provide useful information on facilities and the environment, and support other measurement techniques. The locations of underground steam pipes or other buried heat sources can be made in remote areas. The presence of standing water or high soil water content can absorb (mask) gamma radiation coming from surface radiological contamination. In aerial gamma surveys, the presence of surface water can be detected by infrared spectrometry and adjustments made to the gamma data collected. Soil types can be distinguished by radiometery, because of different heat capacities and emissitivities. Many man-made features (roads, trails, backfill locations, etc.) are discernable from the differences in radiant temperatures. Cooling water discharges from power plants can be mapped remotely using infrared radiometry to determine cooling rates, area of thermal impact, and optimum sampling locations. All these examples show that infrared temperature measurements should be part of any standard sensor suite.

\section{Multi-Spectral Images Applied to Surface Vegetation}

The Charge Coupled Device (CCD) camera systems on-board the UAV outfitted with narrow band-pass filters will permit nearly coincidental collection of vegetation reflectance in the red $(685 \mathrm{~nm})$, green $(550 \mathrm{~nm})$, and near infrared $(800 \mathrm{~nm})$ region of the electromagnetic spectrum. The OS -600 radiometer will provide broad band infrared radiance in the $8000-12000$ $\mathrm{nm}$ region. These data will permit identification of surface features relevant to various activities involved with monitoring and environmental restoration at Department of Energy facilities. Signatures of interest are both direct, in the case of surface temperature, or indirect as is the case when vegetation vigor is used to infer contamination levels underground.

The specular or direct component of leaf reflectance is determined by leaf orientation and the surface characteristics of the leaf. The diffusive component of leaf reflectance is derived by multiple scattering of radiation within the leaf structure. The total reflectance of healthy plants 
leaves is relatively low in the visible portion of the spectrum, $400-700 \mathrm{~nm}$, where light absorption by leaf pigments dominate. Stressed or damaged plants with reduced photosynthesis exhibit increased reflectance in the red region of the visible spectrum. In the near and middle infrared regions, these pigments are transparent and the internal leaf structure controls reflectance. Reflectance in the near infrared, $700-1300 \mathrm{~nm}$, is characterized by relatively high values of reflectance. Middle infrared reflectance, $1300-3000 \mathrm{~nm}$, is attenuated by the water content of the leaf. These attributes of the infrared spectrum can be utilized to identify plant species. $(5,6)$

Techniques for remote sensing of vegetation vigor include determination of several different vegetation indices that use red and near-infrared reflectance. $(7,8)$ Two frequently used indices are the simple ratio, $S R=R r / R n i r$, and the normalized difference, $N D=(R n i r$ $\mathrm{Rr}) /((\mathrm{Rnir}+\mathrm{Rr})$, where $\mathrm{Rr}$ and $\mathrm{Rnir}$ are the reflectance in the red and near-infrared regions.

Soil surface temperatures are influenced by soil moisture and contamination by petroleum products when compared to dry or uncontaminated soil. Temperature of plant canopies as determined from remote sensing of infrared energy in the mid-range $(3000-5000 \mathrm{~nm})$ and longrange $(8500-12500 \mathrm{~nm})$ have been shown to be indicative of water stress. $(9,10)$

\section{Conclusions}

There is a need to provide safe, accurate, and cost-effective remote monitoring of physical and chemical conditions at various contaminated sites at DOE facilities. A small unmanned aircraft monitoring platform provides the greatest benefit in speed, personnel safety, and cost savings. For example, a small drone aircraft contaminated by airborne materials poses less of a disposal problem than manned aircraft. A helicopter is of greater utility than a fixed-winged aircraft due to the ease of launch and recovery, the low air speed and altitude, and the hovering capability of a helicopter. The demonstrations at SRS will provide proof of principle verification of this technology by conducting precise measurements of surface temperatures and radiation levels at locations that have been well characterized by ground surveys.

\section{References}

1. National Uranium Resource Evaluation Preliminary Report, DOE-GJ, Document Nos. GJ-11, 1976 and DOE-GJBX-77, 1977.

2. K. D. Peterson, D. G. Wagner, and C. R. Ward, "An Autonomous Mobile Robot to Perform Waste Drum Inspections”, Report WSRC-MS-93-440X, (1993).

3. E. L. Feimster, "An Aerial Radiological Survey of the Savannah River Site TNX Facility", Report EGG-10617-1131, June, 1991.

4. A. E. Fritzsche and J. E. Jobst, "Aerial Radiological Surveys of Steed Pond at the Savannah River Site", Report EGG 10617-1192, September, 1993. 
5. D. M. Gates, H. J. Keegan, J. C. Schleter and V.R. Weidner, "Spectral Properties of Plants", Appl. Opt. Vol 4, pp 11-20, 1965.

6. E. B. Knipling, "Physical and Physiological Basis for the Reflectance of Visible and NearInfra-red Radiation from Vegetation", Remote Sens. Environ. Vol 1, pp 155-159, 1970.

7. D. R. Thompson, and O. A. Wehmanen, "Using Landsat Digital Data to Detect Moisture Stress", Photgramm. Eng. Remote Sens. Vol 45, pp 201-207, 1979.

8. R. D. Jackson, R.N. Slater and P. J. Pinter, "Discrimination of Growth and Water Stress in Wheat by Various Vegetation Indices through Clear and Turbid Atmospheres", Remote Sens. Environ. Vol 13, pp 187-208, 1983.

9. S. B. Idso, R. J. Reganato, D. C. Reicosky and J.L. Harfield, "Determining Soil-Induced Plant Water Potential Depressions in Alfalfa by Means of Infrared Thermometry", Agron. J. Vol 73, 826-830, 1981.

10. R. D. Jackson, Advances in Irrigation (D. Hillel, Ed.), Academic, New York, Vol 1, pp 43$85,1982$. 

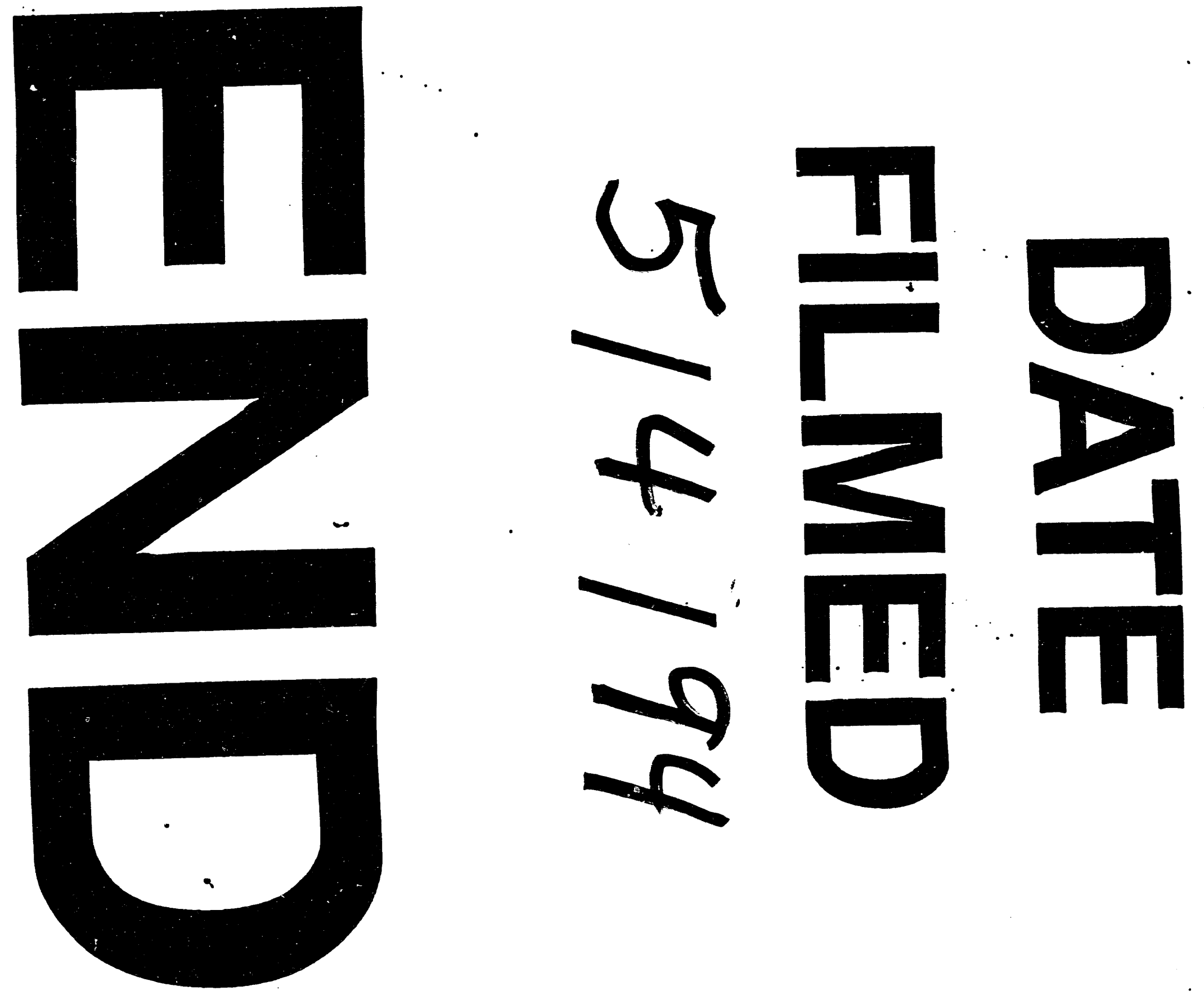